\title{
Stress Analysis Performed in the Near Surrounding of Small Hole by a Digital Image Correlation Method
}

\author{
Martin Hagara*, Róbert Huňady and František Trebuňa \\ Technical University of Košice, Faculty of Mechanical Engineering, Letná 9, 04200 Košice
}

\begin{abstract}
Martin Hagara, Ing. Ph.D., (born in 1985) is a research worker at the Department of Applied Mechanics and Mechanical Engineering, Technical University of Košice, Slovakia. The research, he carries out, is focused on digital image correlation method and its implementation into solving problems of dynamics and stress/strain analysis. He is also interested in some others optical techniques such as electronic speckle pattern interferometry and laser vibrometry. In 2011 he attended a trimestral internship in Dantec Dynamics GmbH in Ulm, Germany. He is the author and co-author of more than 40 publications published in journals, conference proceedings in Slovakia and abroad. He participates in the solving of several grant and state projects.
\end{abstract}

Róbert Huňady, doc. Ing. Ph.D., (born in 1981) is an associated professor of applied mechanics. Since 2010 he has been working at the Department of Applied Mechanics and Mechanical Engineering, Technical University of Košice, Slovakia. In 2009, he attended EC Marie Curie Training Program SIMVIA2 at Czech Technical University of Prague, Czech republic. His professional activity is mainly focused on vibration analysis and modal analysis of mechanical systems and structures. He is also interested in the development of modern optical methods of experimental mechanics such as high-speed digital image correlation, electronic speckle pattern interferometry and laser vibrometry. He is co-author of 2 monographs, 3 university text books and more than 50 publications published in journals, conference proceedings at Slovakia and abroad. He participates in the solving a several grant projects and different tasks in cooperation with the practice.

František Trebuňa, Dr.h.c. mult. prof. Ing. CSc. (1947) is a professor of Applied mechanics, Dean of the Faculty of Mechanical Engineering of Technical university of Košice. He is author of 12 monographs, 13 university textbook, special book publications, 12 university notebooks and more than 350 publications in journals and conference proceedings in Slovakia and abroad. He is also author of important projects and engineering works. His professional and scientific orientation is oriented to experimental and numerical methods of mechanics, prediction lifetime of structure, stress and strain analysis, photoelasticimetry, redistribution of stresses, modal analysis. He received several prizes at home and abroad. He received three honorary Doctor Honoris Causa (Dr.h.c.) including two from foreign universities for the development of applied mechanics and mechatronics and last year he received Honorary Doctorate of Letters (For the extraordinary contribution in the area of creation, development and publication activity in the scientific branches of applied mechanics and mechatronics), IBC Cambridge, England. At the beginning of 2014 he received State prize he got "Honour of Ludovit Štúr of the 2nd order". Prof. Trebuña is a member of several Scientific councils on technical universities in Slovakia and abroad and member of editorial boards of journals.

Abstract: The paper deals with the description of the whole process of stress fields identification performed in the near surrounding of a small hole using digital image correlation. At first the authors simply describe the principles and possibilities of modern optical devices working on digital image correlation principle. After 
then they focus on the analysis of strain fields as well as investigation of the influence of some correlation parameters such as facet size, virtual grid, smoothing and size of the calibration target on the accuracy and quality of the obtained results. As the correlation systems usually serve only for strain analysis, the stress analysis with properly set correlation parameters was done in Q-STRESS V.1.0 a program developed at the authors department. The obtained results were processed in a form of graphs and tables and finally compared with the results achieved numerically using FEM.

Keywords: Digital image correlation; strain analysis; stress analysis; correlation parameters, Q-STRESS.

\section{Introduction}

Optical systems represent in experimental mechanics a very important group of devices allowing full-field deformation analysis. To this group belongs also digital image correlation - a modern non-contact technique with a basic principle based on comparison (denoted as correlation) of digital images captured during the investigated object loading. The heart of the digital image correlation systems is a CCD camera, which captures the random black and white pattern created on the object surface. The obtained images are compared along small picture elements called facets, which size is defined by the user and depends on the resolution of captured images. According to the type of CCD sensor correlation systems can be divided into two fundamental groups - while the high-speed systems reach the sampling frequency of several thousands, 10-thousands or even 100-thousands frames per second and are mainly used in solving problems of dynamics [1-4] the low-speed systems are due to their higher spatial resolution used for deformation analysis [5-7]. The commercial software, delivered together with correlation systems, by which the whole measurement process is controlled, usually allows determine only the displacement and strain fields. For that reason the authors' goal was to create the user-friendly software for Dantec Dynamics correlation systems Q-400 and Q-450, which the authors' workplace is the owner of, allowing visualization not only mentioned fields, but also stress fields. Moreover, the authors would like to point out some aspects, which should be taking into account by deformation analysis per- formed by digital image correlation systems.

\section{Q-STRESS - the Non-commercial Software for Computation and Visualization of Stress Fields}

Q-STRESS V.1.0 is a tool serving for visualization of stress fields obtained by measuring of strain fields using digital image correlation systems Dantec Dynamics. This first version currently allows investigation of plane stresses in elastic domain, however in the near future we will consider how to modify it also for analysis of plastic deformations.

Data exported from the software Istra4D delivered together with correlation systems Dantec Dynamics are in a form of HDF5 files with a structure illustrated in Fig. 1.

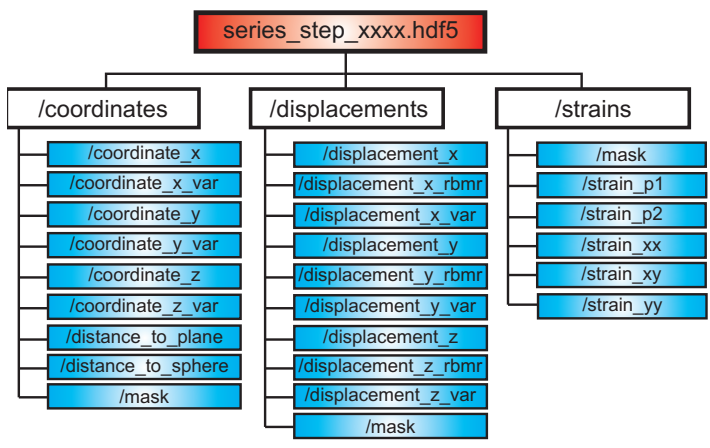

Fig. 1: The structure of HDF5 file exported from Istra4D.

This structure comprise of three main groups (coordinates, displacements and strains), whereby each of them consists of several next datasets containing the amounts of the quantities measured in so-called mask points. These points with value of 1 represent the correlated locations, on the other hand if the value of mask point is 0 , it concerns either unfilled places of the object surface or its parts, which from some reasons (especially contrary illumination conditions) could not be correlated. The total size of the mask is then expressed as a product of maximal quantum of mesh rows and columns.

The process of obtaining stress fields by QSTRESS v.1.0 contains of four phases. In the first phase the measurement has to be evaluated. This phase can be denoted as a pre-processing phase, because it is performed besides Q-STRESS v.1.0 in Istra4D. The next three phases are then accomplished directly in Q-STRESS v.1.0, which interface 
can be seen in Fig. 2. For the reason that HDF5 files can be simply processed in Matlab also the program Q-STRESS V.1.0 was created in this software. Work with the program Q-STRESS V.1.0 comprises of three following phases:

\section{- processing phase (Fig. 2a), \\ - computing phase (Fig. 2b), \\ - visualization phase (Fig. 2C).}

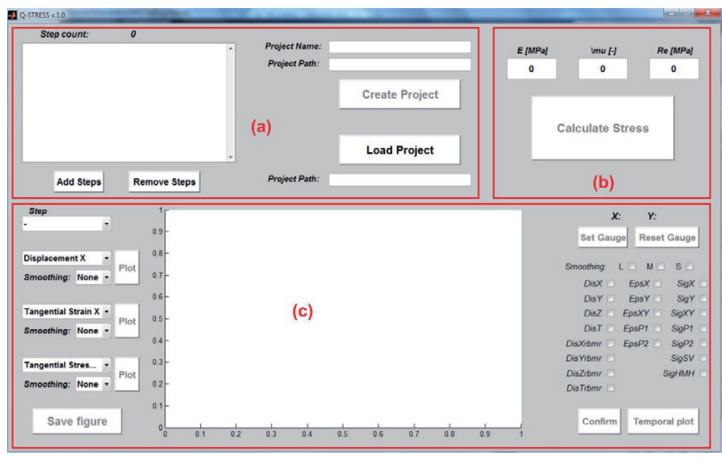

Fig. 2: The interface of Q-STRESS v.1.0: (a) processing phase, (b) computing phase, (c) visualization phase.

In the processing phase it is necessary to read HDF5 files (pushing on the button "Add Steps"), exported from Istra4D, for the creation of matrices needed for calculation of the stresses. After reading of the files the program automatically shows the number of steps used by calculation ("Step Count"). In a case if it is needed to remove one or more steps, it can be done clicking on the button "Remove Steps", after which the selected step is automatically removed from the calculation. When the denomination of the project is entered into the field denoted as "Project Name" the program generates the path, where the project will be save and shows it in the field with a name "Project Path". To this moment the pushbutton "reate Project" is inactive and is activated only in case if the following conditions are fulfilled:

\section{- the number depicted in the field "Step Count" is} minimally equal to 2 ,

- the user correctly enters the name of the project.

Consequently, when the project is created, it has to be read. For this scope the pushbutton "Load Project" is used. During creation of Q-STRESS v.1.0 interface this button was considered for the purposes, that it is not necessary to create the same project on each occasion, when Q-STRESS v.1.0 is restarted. If the project has been created yet, it can be read immediately after the initialization of Q-STRESS v.1.0.

The computing part of the program contains three editable fields, into which it is necessary to enter the parameters, needed for calculation of stresses. It deals about the following parameters:

- Young modulus E [MPa],

- Poisson ratio $\mu$ (denoted as $\backslash \mathrm{mu}$ ) [-],

- Yield stress Re [MPa].

While the first two are necessary for the calculation of stresses, the last serves for identification, whether during the loading does not occur the plastic deformation of the object. After entering of these three values the pushbutton "Calculate Stress" is automatically activated. When this button is clicked on the program calculates the values of normal stresses $\sigma_{\mathrm{x}}, \sigma_{\mathrm{y}}$, shear stress $\tau_{\mathrm{xy}}$, principal stresses $\sigma_{1}$, $\sigma_{2}$ and equivalent stresses $\sigma$ sv (plane Saint-Venant stress) and $\sigma$ нмн (plane Huber-Mises-Hencky stress) for each mask point with the value of 1 .

If the program determines that any calculated value of equivalent stress overpasses the entered amount of "Yield Stress", it displays the announcement "Calculated equivalent stress is higher than entered amount of yield stress" and shows the step number, by which this event happened. As Q-STRESS V.1.0 is limited for the stress investigation in elastic domain, for the next analysis only the steps with lower consecutive number can be used and the creation of a new project has to be begun again.

The last phase is the visualization phase, which is activated immediately when all the mentioned stresses are calculated. In this phase the user can choose the number of step, which he wants to depict. It can be set the visualization of displacement fields, strain fields or stress fields, whereby the user decides, whether the results without smoothing or with low/medium/strong smoothing will be depicted. The chosen field is after clicking on corresponding pushbutton "Plot" illustrated in the area occurring in the center of the bottom part of Q-STRESS v.1.0 interface. Current depicted field can be saved in Matlab format *.fig clicking on the pushbutton "Save Figure".

A virtual gauge is a tool allowing depiction of the temporal change of a chosen quantity. It can be activated pushing the pushbutton "Set Gauge". Thereafter one point on the current field has to be chosen, in which a temporal change of selected quantity will be determined. After selection of 
level of smoothing it is necessary to confirm the choice clicking on the pushbutton "Confirm". Finally the pushbutton "Temporal Plot" is activated serving for depiction of a new figure with temporal plot of chosen quantity.

\section{Deformation Analysis of the Small Hole Sur- rounding Using Q-400 Dantec Dynamics}

For the performing of deformation analysis a low-speed (max. 2fps) correlation system Q-400 Dantec Dynamics was used. Its high spatial resolution (5MPX) makes it possible to use it in the analysis of small objects during their static loading. The analysis was performed on a small surface in the near surrounding of the hole with diameter of $2.5 \mathrm{~mm}$ (see Fig. 4).

For the investigation of small areas it is needed to create a random black and white pattern on the specimen surface with very fine structure. It is not possible to achieve such pattern using the most standard form - spraying black dots on the white background. For that reason the pattern was printed on vinyl foil and attached to the specimen surface [8].

Taking into account that by investigation of such small surfaces it is necessary to configure the cameras to the specimen as closely as possible the best solution seemed to be the avoidance of robust loading systems and realization of the measurements in the laboratory conditions. The loading was thus performed with mechanical loading system working on lever mechanism with attached force transducer HBM RSCC/200kg (see Fig. 3).

The specimen was due to relatively small available loading forces made from material PS-1 with the thickness of $3.05 \mathrm{~mm}$ and following mechanical properties $\mathrm{E}=2500 \mathrm{MPa}, \eta=0,38, \mathrm{Rp}_{0,2}=80 \mathrm{MPa}$, $\rho=1280 \mathrm{~kg} \cdot \mathrm{m}^{-3}$.

In Fig. 4 it is possible to see the image, captured by one of the correlation system cameras, expressing the size of evaluated specimen surface (ca. $6 \times 6 \mathrm{~mm}^{2}$ ). For the illustration this figure similarly depicts chosen facet sizes (12x12px, 16x16px, $20 \times 20 p x, 24 \times 24 p x$ and $28 \times 28 p x)$ used for the evaluation of the measurements.

The specimen was loaded in y-direction by a tension force varying from $0 \mathrm{~N}$ to maximal value $700 \mathrm{~N}$ with constant increment of $50 \mathrm{~N}$, by which the snapshots were captured in manual mode. Correlation system thus besides the reference image

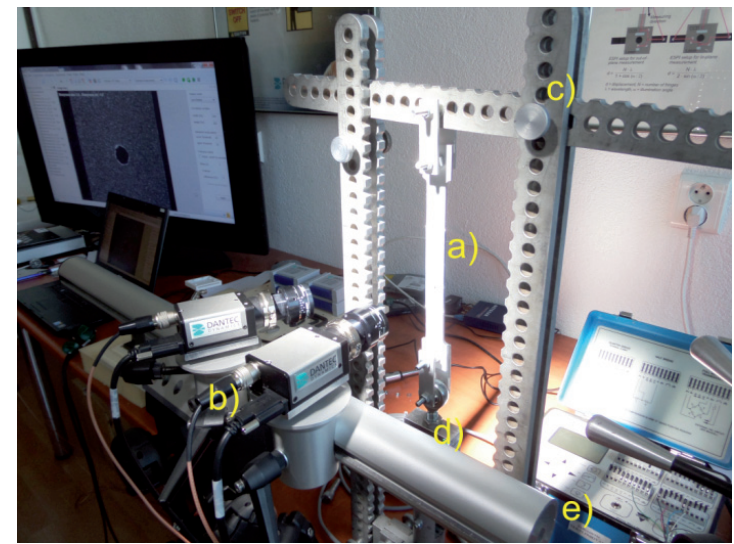

Fig. 3: Configuration of the measuring apparatus: a) specimen, b) two-cameras system Q-400, c) mechanical loading system, d) force transducer HBM RSCC/200kg, e) indicator Vishay P3.

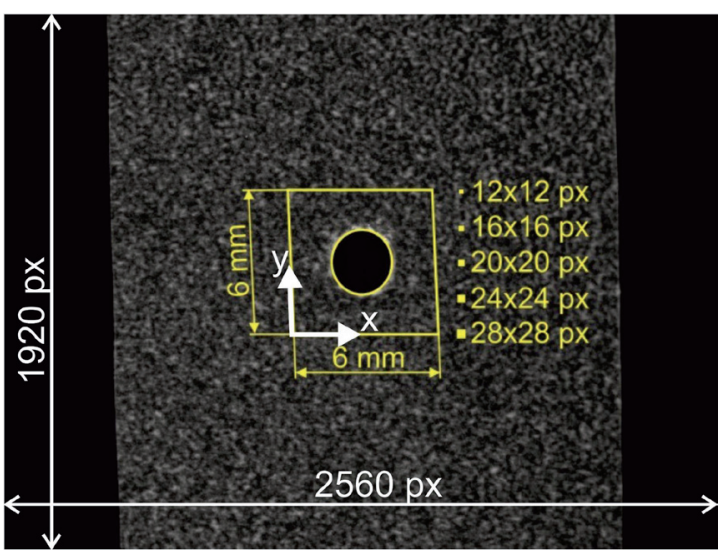

Fig. 4: The image captured by one of the cameras illustrating the size of the evaluated specimen surface with chosen facet sizes used for evaluation.

(without loading) captured next fourteen loading states of specimen. For the identification of the tension force amount the tenzometric equipment Vishay P3 was used.

\subsection{Influence of Facet Size and Smoothing on the Re- sults of Deformation Analysis}

Following rows will be referred to the investigation of influence of some correlation parameters on the quality of the obtained results. Firstly the effect of facet size and corresponding virtual grid size, in which corners the displacements are calculated, will be demonstrated.

For the calibration of the correlation system with stereoscopically arranged cameras, what means founding of their intrinsic and extrinsic parameters such as focal length, principal point and their rela- 
tive location as well as rotation, a calibration target with $9 \times 9$ squares of size $1 \mathrm{~mm}$ was used. These correctly estimated data are a fundamental for the right projection of three-dimensional coordinates of investigated object points into two-dimensional coordinates of sampled images. Fig. 5 demonstrates the course of mean approximated error radius determined by the evaluation of the measurement performed in Istra4D using commonly used facet sizes: 12x12px, 14x14px, 16x16px, 18x18px, $20 \times 20 p x, 22 \times 22 p x, 24 \times 24 p x, 26 \times 26 p x, 28 \times 28 p x$ and $30 \times 30 p x$.

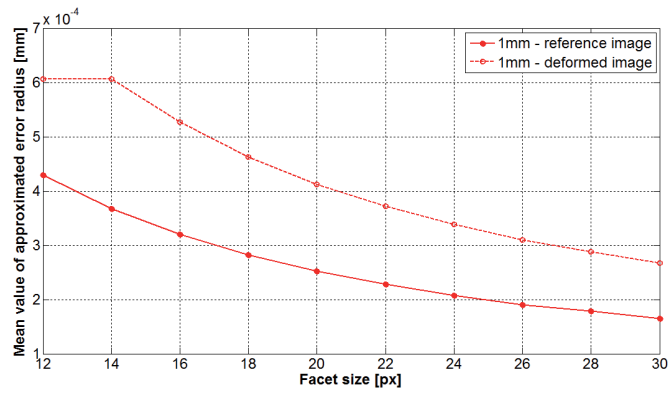

Fig. 5: Influence of the facet size on the mean value of approximated error radius.

It can be concluded that the biggest error radius is estimated by the use of the smallest facet size and it decreases with the increasing facet size. The error radius is even bigger, when the specimen is deformed. For these reasons the choice of higher facet size should give more accurate results.
However, let us show what happened with the evaluated object contour by increasing facet size. Tab. 1 shows how the number of correlated facets and corresponding diameter of the evaluated hole is changing with increasing facet size.

Table 1: Influence of the facet size on the number of evaluated facets and corresponding diameter of the reconstructed hole.

\begin{tabular}{|c|c|c|c|}
\hline $\begin{array}{c}\text { Facet size } \\
{[\mathbf{p x}]}\end{array}$ & $\begin{array}{c}\text { Virtual grid } \\
{[\mathbf{p x ]}}\end{array}$ & $\begin{array}{c}\text { Number of } \\
\text { facets [-] }\end{array}$ & $\begin{array}{c}\text { Diameter of } \\
\text { the hole [mm] }\end{array}$ \\
\hline $12 \times 12$ & $9 \times 9$ & 4667 & 2.63 \\
\hline $14 \times 14$ & $10 \times 10$ & 3093 & 2.68 \\
\hline $16 \times 16$ & $12 \times 12$ & 2578 & 2.71 \\
\hline $18 \times 18$ & $14 \times 14$ & 1873 & 2.73 \\
\hline $20 \times 20$ & $15 \times 15$ & 1417 & 2.75 \\
\hline $22 \times 22$ & $17 \times 17$ & 1243 & 2.85 \\
\hline $24 \times 24$ & $18 \times 18$ & 1099 & 2.90 \\
\hline $26 \times 26$ & $20 \times 20$ & 878 & 2.91 \\
\hline $28 \times 28$ & $21 \times 21$ & 721 & 2.92 \\
\hline $30 \times 30$ & $23 \times 23$ & 649 & 2.95 \\
\hline
\end{tabular}

On the other hand, let us see what the changing facet size caused with the evaluated strain fields. Istra4D computes the strains either from the facet deformation, or if the ACSP filters working on adaptive spline polynomial algorithm are used, the strains are computed from deformation gradient. The lowest level of smoothing is equal to $3 \times 3$, smoothing set to $31 \times 31$ gives the most smoothed results. The smoothing levels in Q-STRESS v.1.0 are created as a combination of filters "Lowess" and "Loess" in such a way to correspond the levels of ACSP filters $11 \times 11,21 \times 21$ and $31 \times 31$. The influence of facet size on the results of strain analysis can be seen in Fig. 6, where the various strain fields were obtained

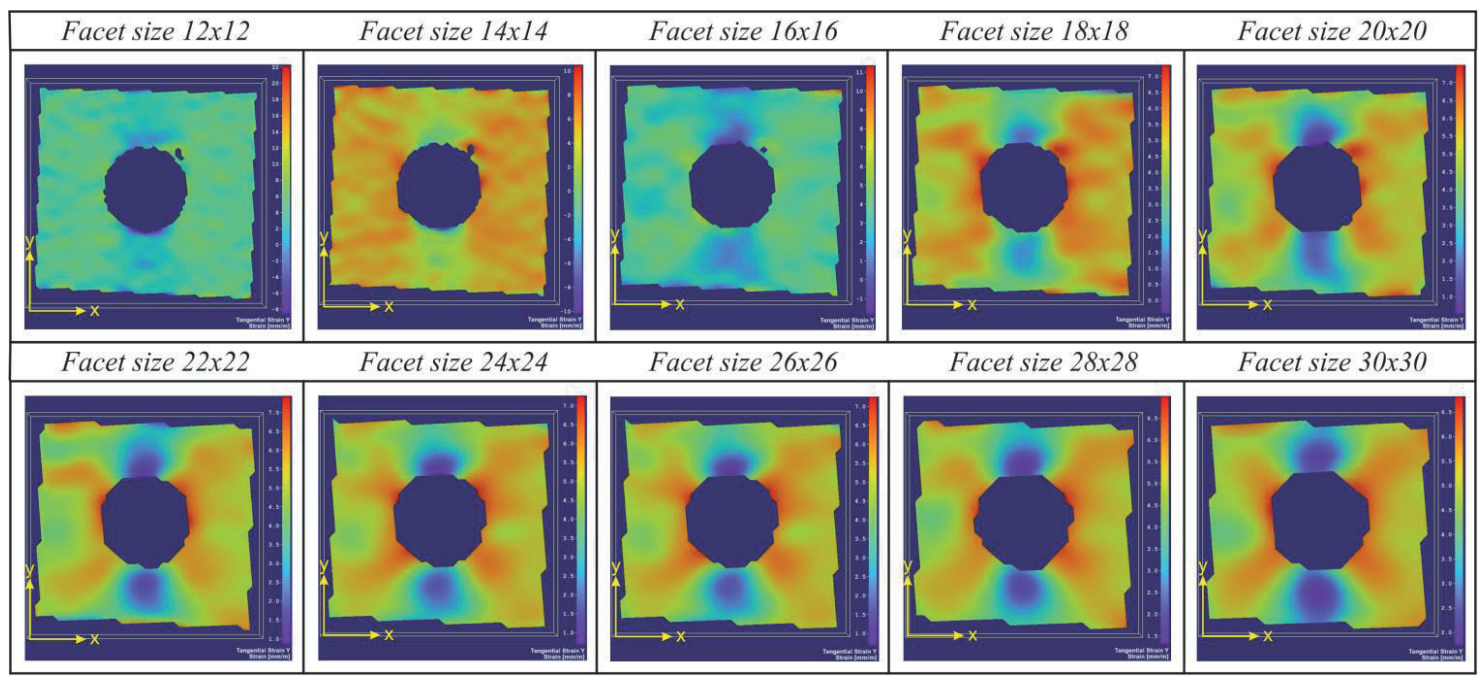

Fig. 6: Fields of tangential strain cy obtained for variously adjusted facet size. 
by the same loading force, variously adjusted facet size and identically set level of smoothing.

Our aim was to determine the change of tangential strains $\varepsilon_{\mathrm{x}}$ and $\varepsilon_{\mathrm{y}}$ by variously set level of smoothing and after then find levels of smoothing convenient to particular facet sizes. For that process a function of virtual gage implicit in Istra4D was used (Fig. 7) and the obtained results were compared with the courses obtained in the same location using SolidWorks.

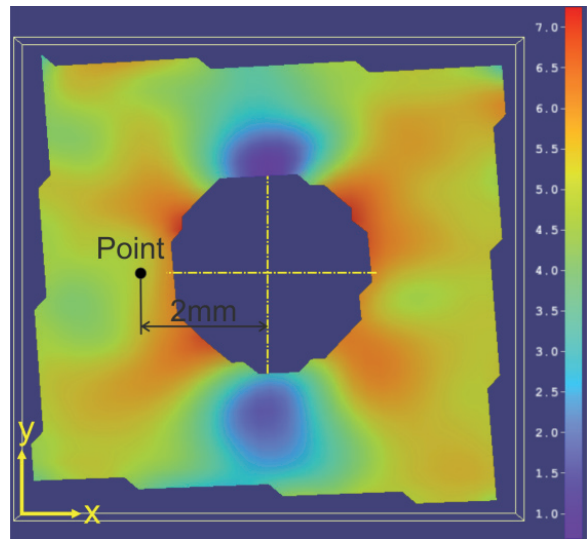

Fig. 7: Point used as a virtual gauge in Istra4D.

It is clear from Fig. 8, which depicted the comparison of the results, that the changing level of smoothing can markedly affect the values of mentioned quantities. The facet size used for evaluation was set to $24 \times 24 \mathrm{px}$.

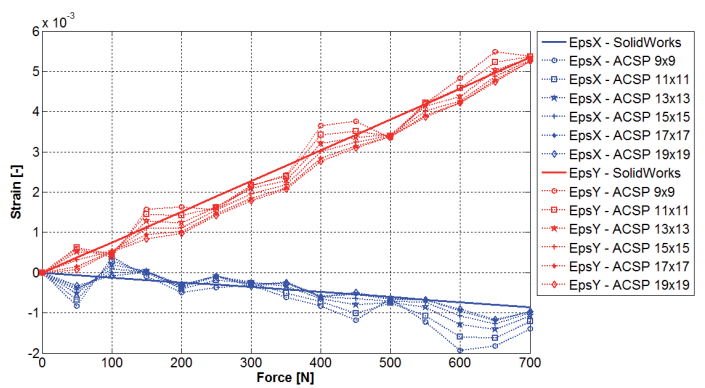

Fig. 8: Courses of tangential strains $\varepsilon x$ and cy obtained for variously adjusted facet size using virtual gauge in Istra4D compared to results obtained numerically.

Fig. 9 illustrates the courses of tangential strains $\varepsilon_{\mathrm{x}}$ and $\varepsilon_{\mathrm{y}}$ obtained in point mentioned above by the variously set facet sizes. The corresponding ACSP filters were adjusted with respect to acquire optimal similarity between courses obtained ex- perimentally and numerically. It seems that the influence of systematical error increasing with decreasing facet size is considerable [9] and thus bigger facets should be more convenient like the smaller ones for the evaluation of strain/stress fields of such small surfaces.

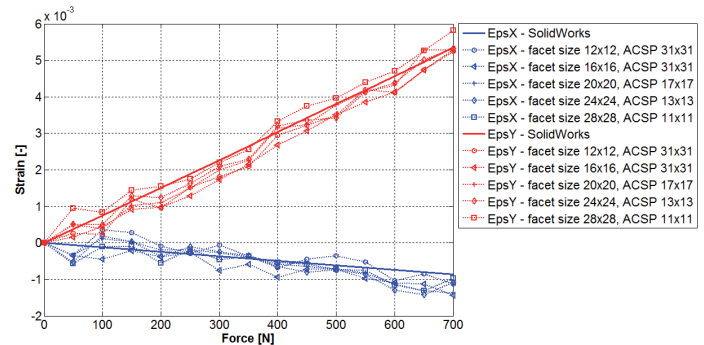

Fig. 9: Courses of tangential strains $\varepsilon x$ and $\varepsilon y$ obtained for variously adjusted facet size and corresponding ACSP filter using virtual gauge in Istra4D compared to results obtained numerically.

\subsection{Influence of the Calibration Target Size on the Re- sults of Deformation Analysis}

The calibration process is correctly performed only with the calibration target with the size corresponding approximately to the size of investigated specimen. As in our instance the investigated specimen was very small, we had just two targets, by which it was possible to calibrate the system. These calibration targets have a checkered shape with $9 \times 9$ fields with the size of $1.0 \mathrm{~mm}$ as well as $1.5 \mathrm{~mm}$.

Calibration residuum is a qualitative parameter computed automatically in Istra4D used for the identification, whether the calibration was performed properly. It expresses the accuracy of the object point projection to the camera image plane. For the calibration performed correctly this quantity should not overpass the amount of $0.5 \mathrm{px}$. During our calibration of the system with calibration target with field's size of $1.0 \mathrm{~mm}$ the calibration residuum reached the value of $0.232 \mathrm{px}$ and with the second one $0.276 \mathrm{px}$, what indicates that both calibrations were done correctly with accuracy sufficient for correct measurement.

Fig. 10 demonstrates the courses of tangential strains $\varepsilon_{x}$ and $\varepsilon_{y}$ obtained in the same point as mentioned above using two different kinds of calibrations targets. The facet size used for evaluation was set to $24 \times 24 \mathrm{px}$. From the presented courses it seems that the influence of calibration target size 
is for this cause irrelevant.

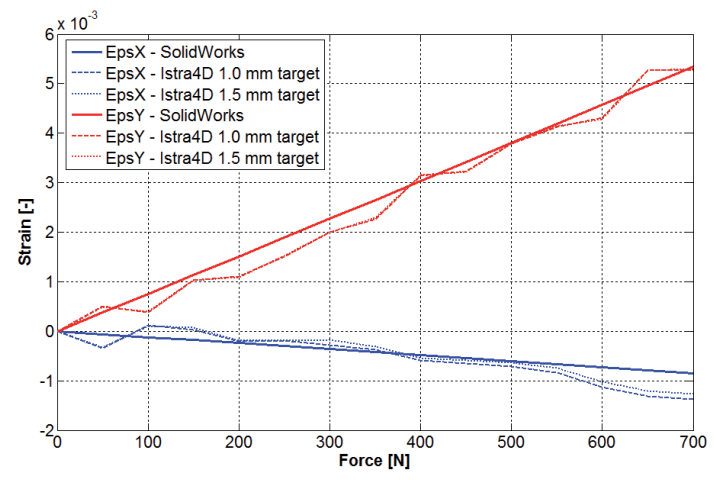

Fig. 10: Courses of tangential strains $\varepsilon x$ and sy obtained by calibration performed with two different calibration targets.

\section{Stress Analysis in the Near Surrounding of the Hole}

From the analysis of the influence of facet size, smoothing and calibration target size on the quality of the results was concluded that the most reliable results of the stress analysis can be obtained with facet size set to higher values. It was necessary to find a convenient compromise to ensure that the evaluated hole will have the diameter similar to the real one. For that reason the measurement was evaluated with the facet size of $24 \times 24 p x$. For cameras calibration the calibration target with the field's size of $1.0 \mathrm{~mm}$ was chosen. Smoothing used in program Q-STRESS V.1.0 was set to the lowest level, which correspond to ACSP filter 11x11.
The stress fields obtained experimentally using Q-STRESS V.1.0 by maximal loading force were compared to stress fields obtained numerically using SolidWorks and the results can be seen in Fig. 11.

In program Q-STRESS v.1.0 a virtual gauge was used in a location denoted as "Point" in Fig. 11 to verify the credibility of the obtained results. The temporal plot of Huber-Mises-Hencky stress obtained in this location was compared to the temporal plot of von Mises stress obtained in the identical point using SolidWorks. As can be seen in Fig. 12 the depicted courses reach the sufficient correspondence adequate to experimentally and numerically obtained results.

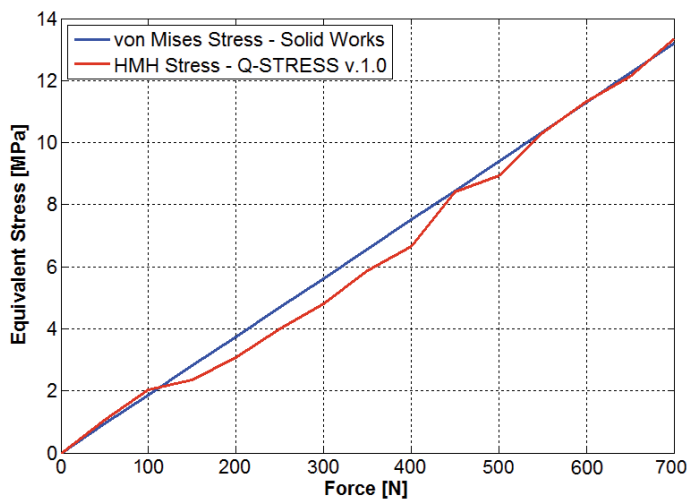

Fig. 12: Comparison of temporal plots of equivalent stresses obtained experimentally using Q-STRESS and numerically using SolidWorks.

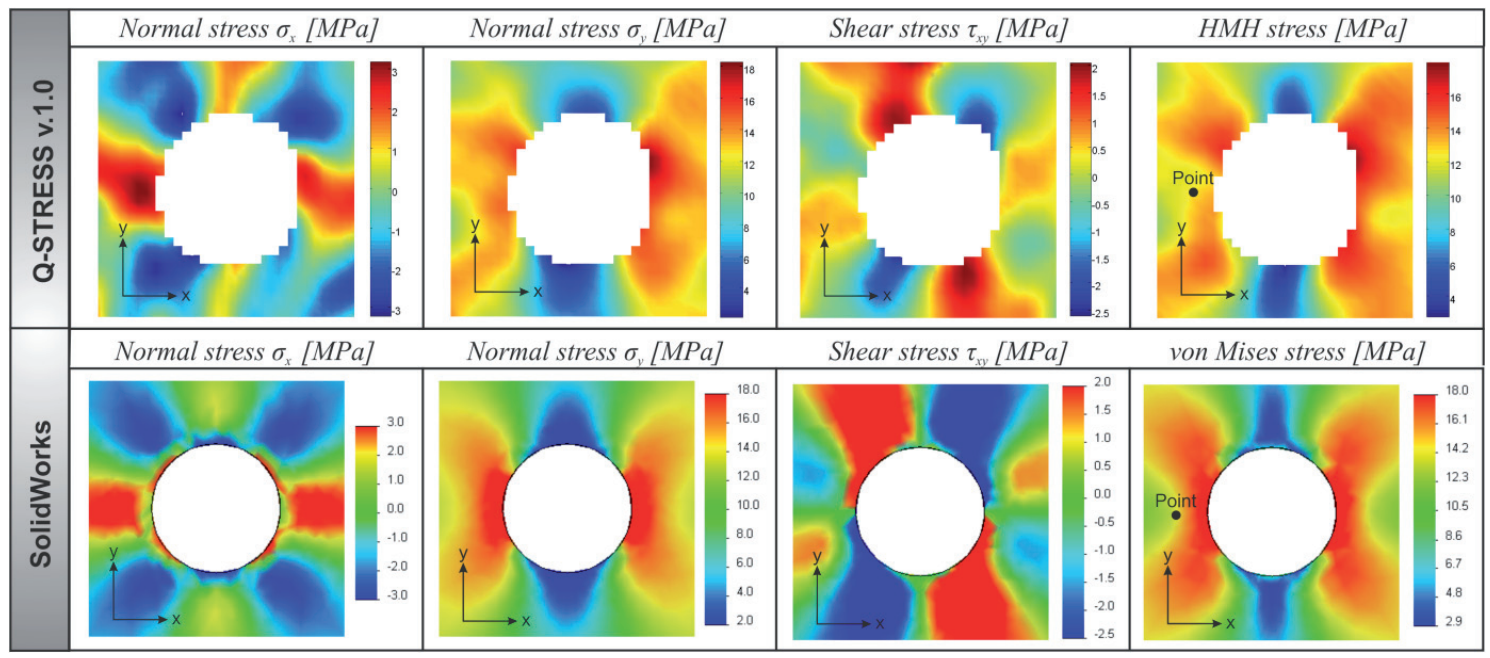

Fig. 11: Comparison of the stress fields in the near surrounding of the hole obtained experimentally using Q-STRESS V.1.0 and numerically using SolidWorks. 


\section{Conclusion}

Digital image correlation is a non-contact and very effective tool serving for full-field deformation analysis. As mentioned the quality of obtained results is strongly influenced by the set of correlation parameters such as facet size, virtual grid size and levels of smoothing and thus any user of digital image correlation systems should pay attention to choose these parameters correctly. This optical method in cooperation with program Q-STRESS v.1.0 becomes a convenient tool for investigation of stress fields. After updating of the program for some new functions and its implementation e.g. into the hole-drilling method it could serve also for the determination of residual stresses. In the near future we are going to attempt to modify QSTRESS v.1.0 to the version enabling investigation of stresses in a plastic domain.

\section{Acknowledgments}

The authors would like to thank to project ITMS: 26220220182 "Univerzitný vedecký park TECHNICOM pre inovačné aplikácie s podporou znalostných technológii".

\section{References}

[1] Trebuňa, F., Hagara, M. (2014). Experimental modal analysis performed by high-speed digital image correlation system. Measurement: Journal of the International Measurement Confederation, 50(1), 78-85.

[2] Trebuňa, F., et al. (2013). Results and experiences from the application of digital image correlation in operational modal analysis. Acta Polytechnica Hungarica, 10(5), 159-174.

[3] Huňady, R., Hagara, M., Schrötter, M. (2012). The Application of High-speed Digital Image Correlation in Vibration Analysis of a Rotating Object In: proceedings of EAN 2012: 50th annual conference on experimental stress analysis. Tábor, Czech republic, 4.6. - 7.6.2012., P. 1-8.

[4] Trebuňa, F., Hagara, M., Huňady, R. (2012). Strain Fields Identification of Chosen Cycling Helmets Types by Their Impact Loading. Acta Mechanica Slovaca, 16(2), 22-30.

[5] Pan, B., Qian, K., Xie, H., \& Asundi, A. (2009). Two-dimensional digital image correlation for in-plane displacement and strain measurement: a review. Measurement science and technology, 20(6), 062001.

[6] Avril, S., Pierron, F., Sutton, M. A., \& Yan, J. (2008). Identification of elasto-visco-plastic parameters and characterization of Lüders behavior using digital image correlation and the virtual fields method. Mechanics of Materials, 40(9), 729742.
[7] Pan, B., Wu, D., Wang, Z., \& Xia, Y. (2011). High-temperature digital image correlation method for full-field deformation measurement at 1200 C. Measurement science and technology, 22(1), 015701.

[8] Hagara, M., Schrötter, M. (2013). The printed patterns investigation for the purposes of deformation analysis performed by digital image correlation system. American Journal of Mechanical Engineering, 1(7), 185-189.

[9] Huňady, R., Hagara, M., Schrötter, M. (2012). Impact assessment of calibration parameters on accuracy method of digital image correlation. Acta Mechanica Slovaca, 16(2), 6-12.

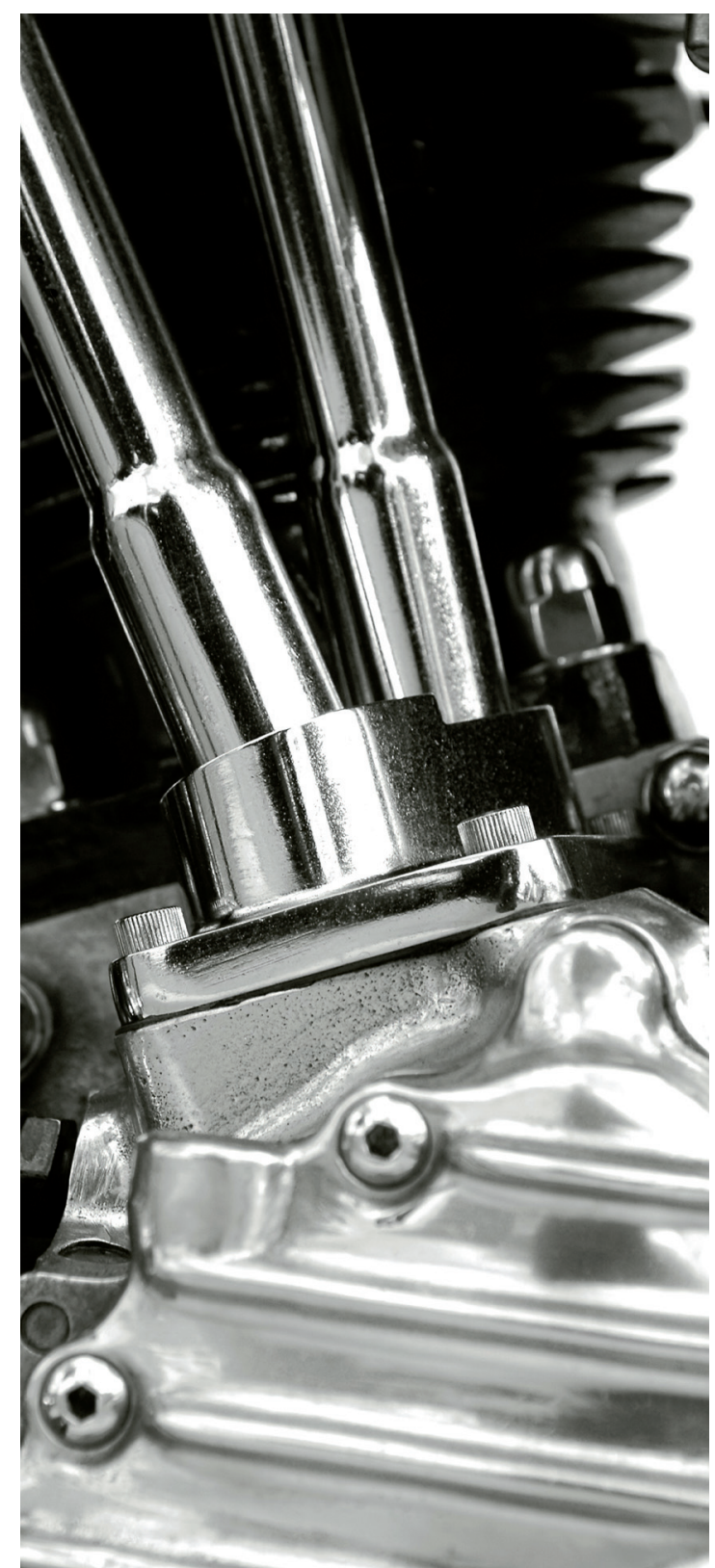

